\title{
Editorial for Special Issue "Critical Metals in Hydrothermal Ores: Resources, Recovery, and Challenges"
}

\author{
Lingli Zhou ${ }^{1,2,3, *}$, Hongrui Fan ${ }^{4,5,6} \mathbb{D}$ and Thomas Ulrich ${ }^{7}$ \\ 1 School of Earth Sciences, University College Dublin, Belfield, Dublin 4, Ireland \\ 2 Irish Centre for Research in Applied Geosciences (iCRAG), University College Dublin, Belfield, \\ Dublin 4, Ireland \\ 3 Geological Survey Ireland, Beggars Bush, Dublin 4, Ireland \\ 4 Key Laboratory of Mineral Resources, Institute of Geology and Geophysics, Chinese Academy of Sciences, \\ Beijing 100029, China; fanhr@mail.iggcas.ac.cn \\ 5 College of Earth and Planetary Sciences, University of Chinese Academy of Sciences, Beijing 100049, China \\ 6 Innovation Academy for Earth Science, Chinese Academy of Sciences, Beijing 100029, China \\ 7 Department of Geoscience, Aarhus University, Hoegh-Guldbergs Gade 2, 8000 Aarhus C, Denmark; \\ thomas.ulrich@geo.au.dk \\ * Correspondence: lingli.zhou@ucd.ie
}

check for updates

Citation: Zhou, L.; Fan, H.; Ulrich, T. Editorial for Special Issue "Critical Metals in Hydrothermal Ores:

Resources, Recovery, and

Challenges". Minerals 2021, 11, 299. https://doi.org/10.3390/min11030299

Received: 20 February 2021

Accepted: 10 March 2021

Published: 13 March 2021

Publisher's Note: MDPI stays neutral with regard to jurisdictional claims in published maps and institutional affiliations.

Copyright: (c) 2021 by the authors. Licensee MDPI, Basel, Switzerland. This article is an open access article distributed under the terms and conditions of the Creative Commons Attribution (CC BY) license (https:// creativecommons.org/licenses/by/ $4.0 /)$.
The consumption of resources has rapidly increased over the last few decades, driven by the continuous growth of the global population and technological innovations. Increasing importance has been put on "Critical" raw materials, which are economically and strategically important but vulnerable to supply shortage [1]. The development of sustainable supplies of critical minerals and metals is required if society is to succeed in the decarbonisation of the global economy. While discovery of critical metal deposits is urgent, of equal importance is understanding the life cycle of critical metals already in the economy. This Special Issue includes contributions on both discovery and investigations of the life cycle of critical metals.

"Critical" raw materials are generally taken to be technology-enabling metals (e.g., cobalt, lithium and rare earth metals), which are referred to as "critical metals", "strategic metals", "E-tech elements" and "technology metals". In contrast to the major industrial, base and precious metals, the role of critical metals in the development of novel technologies, e.g., digital systems and devices, renewable energy and energy storage, electric mobility and autonomous vehicles, and aerospace exploration has increased only in past two decades as a result of the so-called the "Fourth Industrial Revolution" [2].

Criticality assessments of raw materials vary from country to country, and the list of critical raw materials is updated periodically to reflect production, market, technological developments, as well as policy priorities [1]. Although the list varies at the country level, in general there is a global concern of sustainable supply of certain metals. For instance, the United States listed 35 critical minerals that are vital to its security and economic prosperity in 2018, including aluminium ( $\mathrm{Al}$ from bauxite), antimony ( $\mathrm{Sb}$ ), arsenic (As), barite, beryllium (Be), bismuth (Bi), caesium (Cs), chromium $(\mathrm{Cr})$, cobalt $(\mathrm{Co})$, fluorspar, gallium (Ga), germanium (Ge), natural graphite, hafnium (Hf), helium (He), indium (In), lithium $(\mathrm{Li})$, magnesium $(\mathrm{Mg})$, manganese $(\mathrm{Mn})$, niobium $(\mathrm{Nb})$, platinum group metals (PGMs), potash, rare earth elements (REEs), rhenium (Re), rubidium $(\mathrm{Rb})$, scandium $(\mathrm{Sc})$, strontium (Sr), tantalum (Ta), tellurium $(\mathrm{Te})$, tin $(\mathrm{Sn})$, titanium $(\mathrm{Ti})$, tungsten $(\mathrm{W})$, uranium $(\mathrm{U})$, vanadium $(\mathrm{V})$, and zirconium (Zr) [3]. As of 2020, the European Union (EU) has identified 30 critical raw materials that are essential to delivering the European Green Deal, including barite, bauxite (Al), Be, Bi, borates, Co, coking coal, fluorspar, $\mathrm{Ga}, \mathrm{Ge}, \mathrm{Hf}$, heavy REEs (HREEs), In, Li, light REEs (LREEs), $\mathrm{Mg}$, natural graphite, natural rubber, $\mathrm{Nb}$, PGMs, phosphate rock, phosphorus, Sb, Sc, silicon metal, Sr, Ta, Ti, V, W [4]. China's first official policy and catalogue of "strategic minerals" was established in 2016 with the 
list being refined in 2018 to include four sub-groups: 1) the noble metals of $\mathrm{Li}, \mathrm{Be}, \mathrm{Rb}$, $\mathrm{Cs}, \mathrm{Nb}, \mathrm{Ta}, \mathrm{Zr}, \mathrm{Hf}, \mathrm{W} ; 2$ ) the rare earth metals of $\mathrm{La}, \mathrm{Ce}, \mathrm{Pr}, \mathrm{Nd}, \mathrm{Sm}, \mathrm{Eu}, \mathrm{Gd}, \mathrm{Tb}, \mathrm{Dy}, \mathrm{Ho}$, Er, Tm, Yb, Lu, Sc, Y; 3) the companion metals of Ga, Ge, Se, Cd, In, Te, Re, Tl; 4) the precious metals of PGMs, Cr, Co [5]. Mineral deposits that produce those critical metals are accordingly defined as "Critical Mineral Resources" [5]. As pointed out by Andersson [6], the difference in criticality assessments from Western countries and those from China may lie in the consideration of the factor of supply risk. Supply risk is always a key factor to determine criticality in countries (e.g., EU and US) that have a high dependency on imported raw materials, while it is a subordinate factor in Chinese assessments, as some of the strategic minerals and metals are not subject to shortage of supply, at least in the short to medium term.

Some of the critical metals defined above are typically distributed in low concentrations in Earth's crust while others like aluminium are not. A number of the critical metals, such as $\mathrm{Bi}, \mathrm{Co}, \mathrm{Ga}, \mathrm{Ge}, \mathrm{Sb}$, and $\mathrm{Te}$ are currently produced exclusively as the by-product of the extraction of major industrial metals such as $\mathrm{Cu}, \mathrm{Pb}, \mathrm{Zn}$ and Al. The enrichment of critical metals in rocks or minerals to economically viable ores usually requires complicated and prolonged geological processes that lead to their high concentrations in a restricted domain of Earth's crust. For instance, an economic deposit of chromium must contain between 4000 and 5000 times (concentration factor) the average crustal abundance (96 ppm), that is between 38.4 and $48 \mathrm{wt} . \% \mathrm{Cr}$, to be economical. The high concentration factor may explain the apparent scarcity of certain critical metal resources (e.g., PGMs, REEs), although this parameter is usually market dependent for a metallic/non-metallic commodity. In general, a geological process of ore formation combines extraction of the constituents from magmas, rocks or ocean water, transport of the constituents in a fluid medium from the source region to the deposition site, and deposition of the constituents at favourable sites. The ore-forming processes may be broadly grouped into the following categories on the basis of different geological dynamics: (a) orthomagmatic processes, (b) sedimentary processes, (c) metamorphic processes, (d) hydrothermal processes, and (e) surficial and supergene processes [7]. The formation of mineral deposits often involves one or more of these processes. This Special Issue focuses particularly on the hydrothermal processes and its associated critical metal resources, as hydrothermal ore deposits represent a major source of metals.

The aim of this Special Issue is to advance an in-depth understanding of the resources and recovery of critical metals associated with hydrothermal processes. Such knowledge is crucial for both exploration and for exploitation of hydrothermal ores in which these critical metals are present at concentrations sufficient to allow recovery. Ten articles are included in this Special Issue, which are based on empirical studies carried out by researchers from Australia, Chile, Europe, and China, covering a wide range of critical metals, including $\mathrm{Co}, \mathrm{Ga}, \mathrm{Ge}, \mathrm{Re}, \mathrm{REEs}, \mathrm{In}, \mathrm{Sb}, \mathrm{Sn}$ and $\mathrm{W}$. These papers advance our understanding of global critical metal resources, and meanwhile, highlight the challenges for securing these elements moving forward and the necessity for responsible sourcing and sustainable use of these resources.

Hydrothermal processes involve movement of aqueous fluids derived from a variety of sources through the Earth's crust, capable of carrying and/or leaching a variety of elements. The interaction of hydrothermal fluids with wall rocks and/or the hydrosphere may result in the formation of a wide range of mineral deposit types. Two papers in this issue deal with the chemical signature of minerals that can be used to delineate the hydrothermal processes in different deposits. Cave et al. [8] investigate the geochemistry of sulphide minerals in the sediment-hosted Hilton $\mathrm{Zn}-\mathrm{Pb}$ deposit, located at the late Paleoproterozoic to early Mesoproterozoic McArthur Basin of Northern Australia. Six texturally distinct generations of sphalerite were identified through field and microscopy observation, and trace element compositions, particularly Ga, Ge, and In, utilizing in situ LA-ICPMS analysis. Another mineral-chemical study was undertaken by Duan et al. [9] on garnet from the Zhuxiling W (Mo) skarn deposit in Southern China examining REE, Sn and W concentrations. The 
authors demonstrate that the trace element concentrations reflect varying physio-chemical conditions of the hydrothermal fluids at the time of garnet precipitation.

Carbonatite-related REE deposits comprise the main source of LREE and $\mathrm{Nb}$ resources in the world. Despite their economic importance, there is still much to learn about them. Liu et al. [10] use thermodynamic modelling to address the physio-chemical conditions of the ore-forming fluids and REE precipitation mechanisms at the world-class Bayan Obo REE-Nb-Fe deposit, China. The Bayan Obo deposit is a carbonatite-related type in which hydrothermal processes have played a significant role in enriching REE. This study presents a detailed paragenetic sequence of REE minerals and utilizes a variety of evidence to constrain the physical conditions (temperature and pressure) of hydrothermal fluids at the time of mineral precipitation. They conclude that multiple pulses of high temperature hydrothermal fluids were required to form the observed mineral assemblages. Focusing on a global context, the review article by Wang et al. [11] summarises the tectonic background, petrology and geochemical characteristics of carbonatite-related REE deposits, emphasising that hydrothermal processes are crucial in upgrading the REE mineralisation.

The nature and composition of the ore-forming fluids, as well as the age of mineralisation of the quartz vein-type Baiyinhan tungsten deposit, NE China, are elucidated by Wang et al. [12]. The authors employed a number of analytical techniques to analyse hydrothermal quartz, molybdenite, and wolframite. Their results indicate the importance of both hydrothermal and meteoric fluids in ore genesis.

Deep-sea pelagic sediments may be extremely enriched in REEs and Y (REY) and could represent a prominent future source of these critical metals. Zhou et al. [13] use detailed investigations of the sediments to demonstrate the importance of early hydrothermal fluids to metal enrichment.

The tectonic evolution of sedimentary basins from extension to compression has been regarded as the key factor in the formation of sandstone-type uranium deposits. Such a genetic relationship is addressed in the work of Yang et al. [14] in this Special Issue who investigate the sandstone-hosted Qianjiadian U deposit, Songliao Basin, NE China, as a case study. They suggest that weathering and alteration of mafic intrusions in the basin may have been critical in forming a reducing barrier capable of precipitating uranium.

Lemière et al. [15] evaluate the potential of soil analysis for Sb by pXRF (portable $\mathrm{X}$-ray fluorescence) as a low-footprint exploration method based on a case study of the vein-type Les Brouzils ore deposit of western France. The team performed shallow-soil sampling along profiles across known veins in what is now as an agricultural area to capture endogenic geochemical anomalies. The study demonstrates that the pXRF instrument can effectively locate the $\mathrm{Sb}$ veins and precisely delineate $\mathrm{Sb}$ anomalies especially when using its multi-element capabilities.

The green mining concept promotes innovative technologies to simultaneously improve the mining sector's economic and environmental performance [16]. Responses could include extraction of additional critical elements from current production or from historic mine wastes. This Special Issue presents two such studies. One describes the development of technological innovations that allow for the extraction of critical and precious metals associated with low-grade porphyry ores (e.g., $\mathrm{Co}, \mathrm{Te}, \mathrm{Au}, \mathrm{Ag}$ ) [17]. Velásquez et al. [17] use the world-class porphyry Los Sulfatos deposit, located in the Chilean Central Andes, as a case study, and performed in situ and high-resolution geochemical characterisation of the metal-bearing sulphides by LA-ICPMS, the knowledge of which is informative for selective metal treatment. The second study demonstrates extraction of copper from lead and silver mine waste dumps by using a simple, robust, and versatile leaching process [18]. Terrones-Saeta et al. [18] investigated the mine wastes from the mining district of Linares, Spain, and carried out leaching experiments in low molarity of sulphuric acid solutions, at ambient temperature and atmospheric pressure. The results show that the $\mathrm{Cu}$ recovery rate can reach up to approximately $80 \%$, together with almost total recovery rate of $\mathrm{Zn}$.

On the basis of this Special Issue's findings, we outline the following major challenges and opportunities facing academic research and industrial mineral exploration: 
1. An improved understanding of the geochemistry of critical metals is required. Little is known about what the levels of abundance of critical metals are in different geological reservoirs; what ligands are key, and complexes they form in different hydrothermal fluids; and what physical conditions are required for efficient transport of critical metals in hydrothermal fluids? What changes in the hydrothermal fluids can cause the deposition of critical metals? How do critical metals partition into different minerals from the hydrothermal fluids? Evolutionary and revolutionary analytical techniques will need to be developed to be able to precisely determine the critical metal contents in minerals and rocks, which are usually present at extremely low concentrations, and most importantly, to be able to differentiate the primary sources of critical metals. Experimental studies of the chemistry of critical metal transport and deposition by ore-forming fluids are also essential.

2. Refined genetic models of critical mineral deposits need to be developed. Most of the existing genetic models of ore deposits were developed for major industrial metals, while the processes responsible for the critical metal mineralisation have been neglected. Studies of critical metals at the element, the mineral and the deposit scales need to be integrated and combined with other datasets to develop refined genetic models. The results need to be interpreted in ways that are applicable for both the academic research and industry exploration.

3. Knowledge of fertility indicators of critical metal deposits is still absent. Why are some rocks more fertile than others to source/host critical metal mineralisation? How can we develop a vector tool by using mineral geochemistry for the exploration of critical metal resources? In this regard, applying machine learning to large geochemistry datasets of both barren and fertile minerals and rocks will be able to provide a new perspective on rock fertility and mineral discriminators in critical mineral exploration.

4. The ore grades are expected to decline for mineral deposits over time, which implies that significantly more materials will have to be mined and processed to produce the same amount of metal. Thus, a significant challenge for the contemporary mining industry is to move from traditional major industrial metal mining to a highly efficient multi-metallic operation. Innovation in metal-selective metallurgical processing is necessary for cost-effective simultaneous extraction of both major industrial metals and critical metals. This calls for highly interdisciplinary collaboration among geochemists, mineralogists, metallurgists, and engineers.

5. The recovery of critical metals from mining waste and unconventional sources represents a big potential for sustaining the supply of critical metals. However, the challenge lies in the fact that the traditional techniques to recover the critical metals from mine wastes are costly and energy and time consuming. Novel and advanced techniques are required to enable more sustainable and manageable extracting process of critical metals.

This Special Issue was completed while more than half of the world was under lockdown due to the COVID-19 crisis. Critical minerals and metals are widely used in the pharmaceutical industry (e.g., phosphates, platinum), telecommunications industry (e.g., indium gallium, and caesium), and the robotics industry (e.g., rare earth metals, cobalt, and gallium) all of which have been critical in combating this crisis. The editors of this issue hope that it will help shape new thinking to address contemporary societal challenges such as the pandemic and the larger climate and biodiversity challenges that lie ahead.

Funding: This research received no external funding.

Acknowledgments: The Guest Editors would like to sincerely thank all authors, reviewers, the Managing Editor Francis Wu and the editorial staff of Minerals for their timely efforts to successfully complete this Special Issue. We also thank Paul Sylvester, the Editor-in-Chief, for his support. Lingli Zhou is also grateful to Murray Hitzman for his constructive comments and suggestions during the drafting of this editorial.

Conflicts of Interest: The authors declare no conflict of interest. 


\section{References}

1. National Research Council Minerals (NRC). Critical Minerals, and the US. Economy; National Academies Press: Washington, DC, USA, 2008.

2. Cugurullo, F. Frankenstein Urbanism: Eco, Smart and Autonomous Cities, Artificial Intelligence and the End of the City; Routledge: London, UK, 2021.

3. DoI, U.S. Final List of Critical Minerals 2018. Fed. Regist. 2018, 83, 23295-23296.

4. European Commission (EC). Critical Raw Materials Resilience: Charting a Path towards Greater Security and Sustainability; COM 474 Final; European Commission: Brussels, Belgium, 2020.

5. Zhai, M.G.; Wu, F.Y.; Hu, R.Z.; Jiang, S.Y.; Li, W.C.; Wang, R.C.; Wang, D.H.; Qi, T.; Qin, K.Z.; Wen, H.J. Critical Mineral Resources of China: Current Views and Challenges. China Sci. Found. 2019, 2, 106-111. (In Chinese)

6. Andersson, P. Chinese assessments of "critical" and "strategic" raw materials: Concepts, categories, policies, and implications. Extr. Ind. Soc. 2020, 7, 127-137. [CrossRef]

7. Pirajno, F. Hydrothermal Mineral Deposits. Principles and Fundamental Concepts for the Exploration Geologist; Springer: Berlin/Heidelberg, Germany, 1992; Volume XVIII, p. 709.

8. Cave, B.; Lilly, R.; Hong, W. The Effect of co-Crystallising Sulphides and Precipitation Mechanisms on Sphalerite Geochemistry: A Case Study from the Hilton Zn-Pb (Ag) Deposit, Australia. Minerals 2020, 10, 797. [CrossRef]

9. Duan, X.X.; Ju, Y.F.; Chen, B.; Wang, Z.Q. Garnet Geochemistry of Reduced Skarn System: Implications for Fluid Evolution and Skarn Formation of the Zhuxiling W (Mo) Deposit, China. Minerals 2020, 10, 1024. [CrossRef]

10. Liu, S.; Ding, L.; Fan, H.R. Thermodynamic Constraints on REE Mineral Paragenesis in the Bayan Obo REE-Nb-Fe Deposit, China. Minerals 2020, 10, 495. [CrossRef]

11. Wang, Z.Y.; Fan, H.R.; Zhou, L.; Yang, K.F.; She, H.D. Carbonatite-Related REE Deposits: An Overview. Minerals 2020, 10, 965. [CrossRef]

12. Wang, R.; Zeng, Q.; Zhang, Z.; Guo, Y.; Lu, J. Fluid Evolution, HO Isotope and Re-Os Age of Molybdenite from the Baiyinhan Tungsten Deposit in the Eastern Central Asian Orogenic Belt, NE China, and Its Geological Significance. Minerals 2020, 10, 664. [CrossRef]

13. Zhou, T.; Shi, X.; Huang, M.; Yu, M.; Bi, D.; Ren, X.; Yang, G.; Zhu, A. The Influence of Hydrothermal Fluids on the REY-Rich Deep-Sea Sediments in the Yupanqui Basin, Eastern South Pacific Ocean: Constraints from Bulk Sediment Geochemistry and Mineralogical Characteristics. Minerals 2020, 10, 1141. [CrossRef]

14. Yang, D.G.; Wu, J.H.; Nie, F.J.; Bonnetti, C.; Xia, F.; Yan, Z.B.; Cai, J.F.; Wang, C.D.; Wang, H.T. Petrogenetic Constraints of Early Cenozoic Mafic Rocks in the Southwest Songliao Basin, NE China: Implications for the Genesis of Sandstone-Hosted Qianjiadian Uranium Deposits. Minerals 2020, 10, 1014. [CrossRef]

15. Lemière, B.; Melleton, J.; Auger, P.; Derycke, V.; Gloaguen, E.; Bouat, L.; Mikšová, D.; Filzmoser, P.; Middleton, M. pXRF Measurements on Soil Samples for the Exploration of an Antimony Deposit: Example from the Vendean Antimony District (France). Minerals 2020, 10, 724. [CrossRef]

16. Kirkey, J. Eco Friendly Mining Trends for 2014. Available online: https:/ / www.mining-technology.com/features/featureenvironmentfriendly-mining-trends-for-2014-4168903/ (accessed on 29 January 2014).

17. Velásquez, G.; Estay, H.; Vela, I.; Salvi, S.; Pablo, M. Metal-Selective Processing from the Los Sulfatos Porphyry-Type Deposit in Chile: $\mathrm{Co}, \mathrm{Au}$, and Re Recovery Workflows Based on Advanced Geochemical Characterization. Minerals 2020, 10, 531. [CrossRef]

18. Terrones-Saeta, J.M.; Suárez-Macías, J.; Río, F.J.L.D.; Corpas-Iglesias, F.A. Study of Copper Leaching from Mining Waste in Acidic Media, at Ambient Temperature and Atmospheric Pressure. Minerals 2020, 10, 873. [CrossRef] 